\title{
Erratum to: Industrially Prefabricated Cement Spacers: Do Vancomycin- and Gentamicin-impregnated Spacers Offer Any Advantage?
}

Pablo S. Corona MD, Victor Barro MD, Marye Mendez MD, Enric Cáceres PhD, Xavier Flores MD

Published online: 12 December 2013

(C) The Association of Bone and Joint Surgeons( 2013

\section{Erratum to: Clin Orthop Relat Res DOI 10.1007/s11999-013-3342-7}

In the published study by Corona and colleagues, the organism labeled in Tables 2 and 3 as Coagulase-negative
Staphylococcus aureus is incorrect. The organism should be labeled as Coagulase-negative Staphylococcus.

The authors apologize for this error.

The online version of the original article can be found under doi:10.1007/s11999-013-3342-7.

P. S. Corona, V. Barro, M. Mendez, E. Cáceres, X. Flores Department of Orthopaedic Surgery, Hospital Universitario Vall d'Hebron, Universidad Autónoma de Barcelona,

Barcelona, Spain

P. S. Corona, X. Flores

Reconstruction and Septic Surgery Division, Hospital Universitario Vall d'Hebron, Universidad Autónoma de Barcelona, Barcelona, Spain

P. S. Corona $(\square)$

Department of Orthopaedic Surgery, Hospital de Traumatología y Rehabilitación Vall d'Hebron, Passeig Vall d'Hebron 119-129, 08035 Barcelona, Spain

e-mail: pcorona@vhebron.net 